\title{
Premotor Spinal Network with Balanced Excitation and Inhibition during Motor Patterns Has High Resilience to Structural Division
}

\author{
Peter C. Petersen, Mikkel Vestergaard, Kristian H. R. Jensen, and Rune W. Berg \\ Faculty of Health and Medical Sciences, Department of Neuroscience and Pharmacology, University of Copenhagen, DK-2200 KBH N, Denmark
}

\begin{abstract}
Direct measurements of synaptic inhibition (I) and excitation (E) to spinal motoneurons can provide an important insight into the organization of premotor networks. Such measurements of flexor motoneurons participating in motor patterns in turtles have recently demonstrated strong concurrent $\mathrm{E}$ and $\mathrm{I}$ as well as stochastic membrane potentials and irregular spiking in the adult turtle spinal cord. These findings represent a departure from the widespread acceptance of feedforward reciprocal rate models for spinal motor function. The apparent discrepancy has been reviewed as an experimental artifact caused by the distortion of local networks in the transected turtle spinal cord. We tested this assumption in the current study by performing experiments to assess the integrity of motor functions in the intact spinal cord and the cord transected at segments D9/D10. Excitatory and inhibitory synaptic inputs to motoneurons were estimated during rhythmic motor activity and demonstrated primarily intense inputs that consisted of qualitatively similar mixed E/I before and after the transection. To understand this high functional resilience, we used mathematical modeling of networks with recurrent connectivity that could potentially explain the balanced E/I. Both experimental and modeling data support the concept of a locally balanced premotor network consisting of recurrent E/I connectivity, in addition to the well known reciprocal network activity. The multifaceted synaptic connections provide spinal networks with a remarkable ability to remain functional after structural divisions.
\end{abstract}

Key words: balanced; half-center; network; reciprocal; spinal; turtle

\section{Introduction}

Synaptic inputs that drive motoneurons during rhythmic motor patterns have been of great interest since the birth of modern neuroscience (Graham Brown, 1924). These inputs are essential for generating any type of movement and provide vital information about the underlying network architecture. The investigation of synaptic inputs has traditionally been performed using indirect measures such as by recording synaptic potentials during different phases of rhythmic motor activity (Shefchyk and Jordan, 1985; Cazalets et al., 1996; Gabriel et al., 2009), systemic pharmacology (Pratt and Jordan, 1987; Talpalar et al., 2011), lesioning (Cangiano and Grillner, 2005), and activity of identified premotor interneurons (Geertsen et al., 2011). Membrane depolarization/hyperpolarization has also been suggested as a measure of excitation(E)/inhibition (I) (Wallén et al., 1993; Hochman and Schmidt, 1998), especially when combined with intracellular chloride injections (Robertson and Stein, 1988).

Received Aug. 5, 2013; revised Dec. 11, 2013; accepted Dec. 30, 2013.

Author contributions: P.C.P. and R.W.B. designed research; P.C.P. and R.W.B. performed research; K.H.R.J. and R.W.B. contributed unpublished reagents/analytic tools; P.C.P., M.V., and R.W.B. analyzed data; R.W.B. wrote the paper.

This work was supported by the Novo Nordisk Foundation (R.W.B.) and The Danish Council for Independent Research Medical Sciences (R.W.B. and P.C.P.). We thank John Hertz and Jørn Hounsgaard for useful discussions.

Correspondence should be addressed to Rune W. Berg, Faculty of Health and Medical Sciences, Department of Neuroscience and Pharmacology, University of Copenhagen, Blegdamsvej 3, DK-2200 KBH N, Denmark. E-mail: runeb@sund.ku.dk.

DOI:10.1523/JNEUROSCI.3349-13.2014

Copyright $\odot 2014$ the authors $\quad 0270-6474 / 14 / 342774-11 \$ 15.00 / 0$
A recent study in the adult turtle has quantified, for the first time, excitatory and inhibitory conductances during rhythmic motor patterns (Berg et al., 2007). It demonstrated concurrent waves of $\mathrm{E} / \mathrm{I}$ during the on cycle, seemingly in contradiction with the half-center model. The cornerstone of the half-center model is reciprocal inhibition (Jankowska et al., 1965; Moult et al., 2013) that does not explicitly encompass the possibility of on-cycle inhibition (see Fig. 1A-E). Nevertheless, concurrent E/I during the on cycle does not contradict the concept of reciprocal inhibition, because inhibition is also detected in the off cycles. Concurrent $\mathrm{E} / \mathrm{I}$ merely indicates the importance of other sources of inhibitory regulation in addition to the basic reciprocal circuitry. Interestingly, an architecture that could provide such input, known as a balanced network, is widespread across regions of the brain and could therefore represent a manifestation of general principles of network organization, which possibly has its evolutionary origin in the spinal cord.

In balanced networks, the membrane potential $\left(V_{\mathrm{m}}\right)$ is depolarizing as $\mathrm{E}$ increases with $\mathrm{I}$, while keeping the $\mathrm{E} / \mathrm{I}$ ratio constant (see Fig. $1 E-G$ ). However, the purpose of such a metabolically expensive mechanism is not yet understood. Balanced networks have been found in the brainstem (Parkis et al., 1999; Magnusson et al., 2008; de Almeida and Kirkwood, 2010), in superior colliculus (Populin, 2005), in invertebrates (Baca et al., 2008; Sasaki et al., 2009), and in the hippocampus (Csicsvari et al., 1999; Atallah and Scanziani, 2009). It is well documented in the neocortex during sensory processing (Borg-Graham et al., 1998; Haider et 

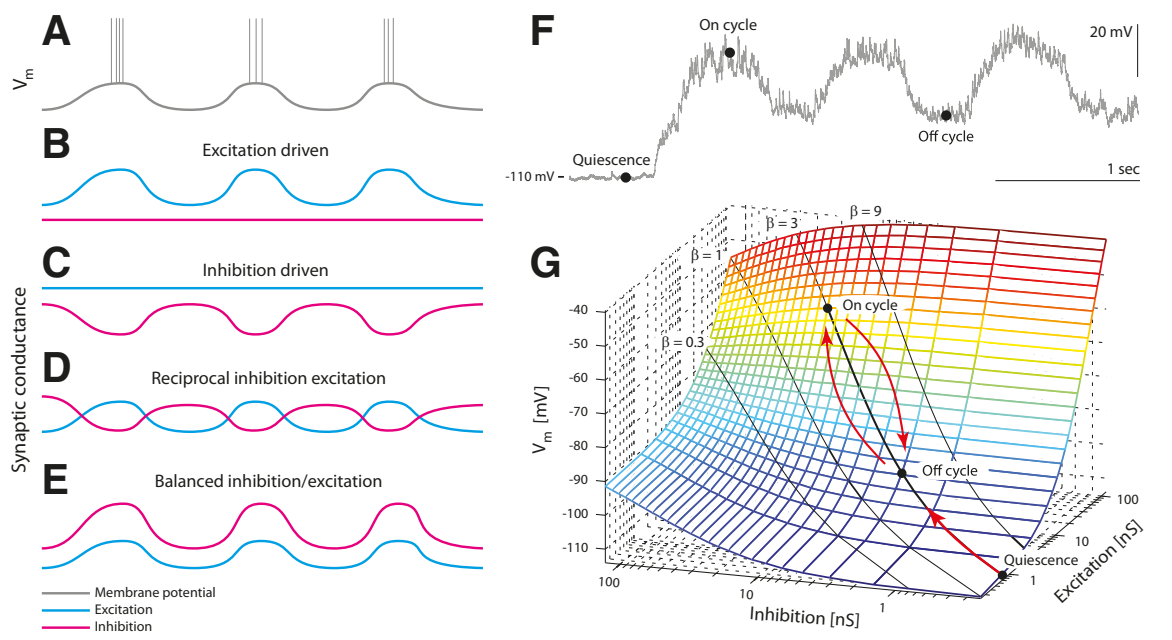

Figure 1. Four possible scenarios of inhibition and excitation leading to the same dynamics in $V_{m} \cdot \boldsymbol{A}-\boldsymbol{D}$, The dynamics in the membrane potential in $\boldsymbol{A}$ is driven mainly by rhythmic excitation $(\boldsymbol{B})$, or mainly by rhythmic inhibition $(\boldsymbol{C})$, or a combination of the two $(\boldsymbol{D})$. $\boldsymbol{E}$, Alternatively, $V_{\mathrm{m}}$ can be driven by balanced excitation/inhibition, where the fraction of $E / /$ conductances $(\beta=$ $\left.G_{\text {exc }} / G_{\text {inh }}\right)$ is kept constant. $F$, Sample intracellular current-clamp recording with negative injection to avoid spikes $\left(I_{\text {inj }}=-2.3 \mathrm{nA}\right)$ defining three states: quiescence (no synaptic input), on cycle (the spike region), and off cycle (midpoint between on cycles). $\mathbf{G}$, When $\beta$ is kept constant, $V_{m}$ will follow the black line (in the direction of red arrows) as the total conductance is waxing and waning [Adapted from Kolind et al. (2012) with permission].

al., 2006), generating high-conductance states (Destexhe et al., 2003). Despite the characterization of such networks in several regions of the brain, the finding of balanced E/I was considered "heterodox" in the turtle spinal cord (Grillner and Jessell, 2009). A similar analysis of E/I drive was performed during neurochemically induced locomotor activity in the neonatal rat spinal cord, and it was reported that inhibition alternated with weak excitation (Endo and Kiehn, 2008). The discrepancy was explained as an artifact recorded in the transected turtle preparation in which the network integrity could have been structurally compromised.

The purpose of the present study was to determine whether the consequential finding of balanced E/I was indeed an experimental artifact. First, we investigated the sensitivity of the network activity to transections at segments D9/D10. If the balanced E/I observed in the original study was attributable to a structural division, then the intact spinal cord should have qualitatively different dynamics lacking balanced activity. Second, we used a network model consistent with the experiments to investigate the ability of networks to maintain their functional integrity when compromised structurally.

\section{Materials and Methods}

\section{Synaptic drive during motor activity}

It is well established that $V_{\mathrm{m}}$ has depolarizing waves during rhythmic motor activity caused by synaptic inputs and possibly aided by intrinsic properties (Stein et al., 1982; Grillner, 2006). What type of synaptic input can cause these slow waves? Traditionally, three categories were considered (Fig. 1): E driven, I driven, and reciprocal E/I. The latter possibility is appealing because of its direct relationship with the classical half-center model (Graham Brown, 1924; Jankowska et al., 1965). However, there is a fourth possibility (Berg et al., 2007), which encompasses the concurrence of $\mathrm{E}$ and $\mathrm{I}$ (Fig. $1 E$ ). In this scheme, $\mathrm{E}$ and $\mathrm{I}$ have simultaneous and opposite pull. Here, it is important to differentiate between the excitability of a neuron and the excitation/inhibition to a neuron. A neuron responding with more spikes to the same input is often misinterpreted as receiving less inhibition and/or more excitation. Nevertheless, this is not necessarily the case. A neuron can be most excitable when it receives most inhibition, as long as the excitation is sufficient to overcome this inhibition. The depolarization in $V_{\mathrm{m}}$ can be explained by the Millman equa- tion, which is the weighted average of conductances with respect to their reversal potentials:

$$
\left\langle V_{m}\right\rangle=\frac{G_{L} E_{L}+G_{e x c} E_{e x c}+G_{i n h} E_{i n h}}{G_{t o t}},
$$

where $\langle\ldots\rangle$ is the time average over a small window; $G_{\text {tot }}, G_{\mathrm{L}}, G_{\text {exc }}$, and $G_{\text {inh }}$, are the total, leak, and mean $\mathrm{E}$ and I conductances, respectively; and $E_{\mathrm{L}}, E_{\text {exc }}$, and $E_{\mathrm{inh}}$ are their reversal potentials. The term balanced $\mathrm{E}$ and I refers to the situation where the ratio between $\mathrm{E}$ and $\mathrm{I}$ is kept constant while varying the synaptic intensity. Thus, if we define the ratio $\beta$ of synaptic conductance $\beta=\frac{G_{e x c}}{G_{i n h}}$, we can rewrite the equation in terms of $\beta$ as follows:

$$
\left\langle V_{m}\right\rangle=\frac{\left(\beta E_{e x c}+E_{i n h}\right) G_{i n h}+G_{L} E_{L}}{G_{t o t}} .
$$

When $G_{\text {tot }}$ becomes large $\left(G_{\text {tot }} \gg G_{\mathrm{L}}\right), V_{\mathrm{m}}$ is approximated

$\left\langle V_{m}\right\rangle \approx \frac{\beta E_{e x c}+E_{i n h}}{\beta+1}$. During quiescence (no synaptic input), $V_{\mathrm{m}}$ will be hyperpolarized (Fig. $1 F$ ). Note that $V_{\mathrm{m}}$ is more hyperpolarized $\left(V_{\mathrm{m}}=-110 \mathrm{mV}\right)$ because of the negative current injection $\left(I_{\text {inj }}=-2.3 \mathrm{nA}\right)$ to avoid spikes, in this instance. When the motor program starts, the synaptic intensity increases, taking $V_{\mathrm{m}}$ rhythmically to the on cycles to initiate spikes, with the off cycles in between (Fig. $1 F$ ). If $\mathrm{E}$ and I are balanced, then the depolarization in $V_{\mathrm{m}}$ will move along a line between the on- and off-cycle points as indicated by red arrows (Fig. 1G). The location of the line will depend on what $\beta$ is. If the initial resting potential is, for example, $V_{\mathrm{m}}=-70 \mathrm{mV}$ and $E_{\mathrm{inh}}=-75$ $\mathrm{mV}$, then any increase in synaptic conductance will depolarize $V_{\mathrm{m}}$ if $\beta>$ $E_{\text {inh }} / E_{\text {rest }}-1=0.07$ (Fig. $1 G$ ). It is difficult experimentally to determine $\beta$ exactly, and it is likely that $\beta$ is only approximately constant in most situations.

\section{Integrated preparation}

Red-eared turtles (Trachemys scripta elegans) of either sex were placed on crushed ice for $2 \mathrm{~h}$ to ensure hypothermic anesthesia. The turtles were killed by decapitation, and blood was substituted by perfusion with a Ringer's solution containing (in $\mathrm{mm}$ ) $120 \mathrm{NaCl}, 5 \mathrm{KCl}, 15 \mathrm{NaHCO}_{3}, 2$ $\mathrm{MgCl}_{2}, 3 \mathrm{CaCl}_{2}$, and 20 glucose, saturated with $98 \% \mathrm{O}_{2}$ and $2 \% \mathrm{CO}_{2}$ to obtain $\mathrm{pH}$ 7.6. The carapace containing the $\mathrm{D} 4-\mathrm{Ca} 2$ spinal cord segments was isolated by transverse cuts (Alaburda and Hounsgaard, 2003; Alaburda et al., 2005), and the cord was perfused with Ringer's solution through the vertebral foramen, via a steel tube and gasket pressing against the D4 vertebra. The spinal column was opened on the ventral side along D8-D10, and the dura mater was gently removed with a fine scalpel and forceps. The pia mater was opened with a longitudinal cut along the spinal cord with the bent tip of a needle. The cut was performed parallel to the ventral horn along the ventral roots. The surgical procedures comply with Danish legislation and were approved by the controlling body under the Ministry of Justice.

Nerve recording and spinal transection. Electroneurogram recordings (ENGs) were performed with suction electrodes. The spinal cord was exposed at D9-S1, and the scratch behavior was recorded before and after transection. The transverse cut was performed at the caudal end of D10 of the spinal cord. The scratch behavior was measured by the activity of the four nerves: hip flexor, knee extensor, $\mathrm{dD} 8$, and hip extensor. The coherence between the nerve activities (see Fig. 3) was calculated as the trial-averaged cross-power spectrum between them, normalized by their root mean power spectra. The coherence values were selected at their dominant frequency in the power spectra. The ENGs were recorded with a differential amplifier, Iso-DAM8. The bandwidth was $100 \mathrm{~Hz}$ to $1 \mathrm{kHz}$. 
Network activation. Mechanical stimulation was performed with the fire polished tip of a bent glass rod. The rod was either mounted onto the membrane of a loudspeaker or controlled with a piezoelectric active stimulator. A function generator controlled the loudspeaker activation: the duration, frequency, and amplitude of the stimulus (Alaburda et al., 2005). A digital step pulse controlled the piezoelectric active stimulator: contraction duration, timing, and number of repetitions and hereby the frequency and amplitude.

Intracellular recordings. Intracellular recordings in current-clamp mode were performed with a Multiclamp 700B and amplifiers (Molecular Devices). Glass pipettes were pulled (P1000; Sutter Instruments) and filled with a mixture of $0.9 \mathrm{M}$ potassium acetate and $0.1 \mathrm{M}$ $\mathrm{KCl}$. For some experiments, the electrodes also contained $4 \% \mathrm{w} / \mathrm{v}$ biocytin. Data were sampled at $20 \mathrm{kHz}$ with a 12-bit analog-to-digital converter, displayed by means of Axoscope and Clampex software. The intracellular recordings were performed with two different methods in the transected and intact preparation. In the transected preparation, the electrodes were inserted into segments D9 and D10 from the caudal end of the transected surface, in parallel with the spinal cord. Motoneurons were directly accessible from the surface at a typical depth of 50-300 $\mu \mathrm{m}$. In the intact preparation, the electrodes were inserted perpendicular to the spinal cord from the ventral side of D9D10. Motoneurons were found at depths ranging from $\sim 300$ to $800 \mu \mathrm{m}$. The electrodes that were inserted through the white matter had less stable resistance than those inserted through the gray matter. Therefore, the electrode resistance was more stable in the transected preparation, but in both preparations there were instances of recordings, which were stable enough for multiple trials, i.e., about $30 \mathrm{~min}$.

Estimating inhibition and excitation. All calculations were performed in Matlab. We used two methods of estimating synaptic conductances: The ohmic method and the auto-correlation function (ACF) method. Both methods rely on intracellular recordings, where $V_{\mathrm{m}}$ is considered stationary within a small window, so $G_{\text {tot }}$ and $\left\langle V_{\mathrm{m}}\right\rangle$ are constant. The methods differ in how $G_{t o t}$ is estimated. The ohmic method uses $V_{\mathrm{m}}$ paired with an injected current, $I_{\text {inj }}$ (Fig. 2A), over at least two or more trials to estimate the slope of the $I / V$ curve (Fig. 2B) (Anderson et al., 2000; Shu et al., 2003; Mariño et al., 2005). This requires that the same network state can be reproduced. In this sample data, the same motor behavior was activated by tactile stimulation (onset indicated by filled triangle). Spikes were removed by lowpass filtering $V_{\mathrm{m}}$ to give an $I / V$ relationship as a function of time, where the slope was $G_{\text {tot }}$ (indicated for two time points in Fig. $2 B$ ). Once $G_{\text {tot }}$ was estimated, we could estimate excitation and inhibition for every point in time (Fig. $2 C$ ) via the following expressions:

$$
G_{\text {exc }}=G_{t o t}-G_{i n h}-G_{L},
$$

where $G_{\text {inh }}$ is given by the following:

$$
G_{i n h}=\frac{G_{L}\left(E_{L}-E_{e x c}\right)+G_{t o t}\left(E_{e x c}-\left\langle V_{m}\right\rangle\right)+I_{i n j}}{E_{e x c}-E_{i n h}} .
$$

$G_{\mathrm{L}}, E_{\text {exc }}, E_{\text {inh }}$, and $E_{\mathrm{L}}$ are assumed constant. The major contribution to membrane conductance is assumed synaptic, such that the total conductance is $G_{\text {tot }}=G_{\mathrm{L}}+G_{\text {exc }}+G_{\text {inh }}$. The resulting time-dependent $G_{\text {tot }}$ (Fig. $2 C$, gray), $G_{\text {inh }}$ (Fig. $2 C$, magenta), and $G_{\text {exc }}$ (Fig. $2 C$, cyan) using Eqs. 3 and 4 are shown. Linearity should be assessed, for instance, by plotting the estimates for different depolarizations against each other (Fig. 2D). The above expressions are based on the assumption that $V_{\mathrm{m}}$ is stationary, such that the derivative is zero in a one-compartment scheme giving the following:

$$
\begin{array}{r}
C_{m} \frac{d\left\langle V_{m}\right\rangle}{d t}=-G_{L}\left(\left\langle V_{m}\right\rangle-E_{L}\right)-G_{\text {exc }}\left(\left\langle V_{m}\right\rangle-E_{\text {exc }}\right)-G_{\text {inh }}\left(\left\langle V_{m}\right\rangle-E_{\text {inh }}\right) \\
+I_{\text {inj }} \approx 0, \quad \text { (5 }
\end{array}
$$

where the mean membrane potential, $\left\langle V_{\mathrm{m}}\right\rangle$, is entered instead of $V_{\mathrm{m}}$ itself. $C_{\mathrm{m}}$ is the membrane capacitance.

The alternative method of estimating $G_{\text {tot }}$, the ACF method, is based on the time constant $\left(\tau_{\mathrm{m}}\right)$ of the fluctuation in $V_{\mathrm{m}}$, using the fact that $G_{\text {tot }}=C_{\mathrm{m}} / \tau_{\mathrm{m}}$ (Berg and Ditlevsen, 2013). The time constant is estimated via the decay in the autocorrelation function, hence the ACF method. This can conveniently be done on single-trial data for small windows. Two windows are highlighted with individual ACF decays in Figure 2E. This method is useful when experimental circumstances do not allow reproduction of same-state or different current injections. When applying both methods on the same data, there was a significant correlation between the estimates $(r=0.64, p \ll 0.001)$. Part of the uncoupled variance is attributable to asymmetry in number of trials in the two methods; the ohmic estimate is based on three trials, whereas the ACF estimate is based on only one trial, making it more prone to statistical 
fluctuations. Thus, the ohmic method is preferable when the trial-to-trial variability is small, and the ACF method is preferable when it is large. We recommend using both measures when possible. For the intact preparation, stable recordings usable for multitrial analysis were rare. The majority of the estimation of conductance was, therefore, accomplished via the ACF method. In the few cases where the ohmic method was possible, the first five peaks of the traces were aligned around the peaks in $100 \mathrm{~ms}$ windows.

\section{Estimating reversal potentials and leak}

$G_{\mathrm{L}}$ was estimated in each trial as the total conductance during quiescence $\left(G_{\mathrm{L}}=25-80 \mathrm{nS}\right)$. The estimates of $G_{\mathrm{L}}, G_{\mathrm{inh}}$, and $G_{\text {exc }}$ rely on the simplifying assumption that leak, inhibition, and excitation are homogeneously distributed over the soma-dendritic surface and that each of these conductances can be represented by a single reversal potential, i.e., the one-compartment model. For the sample data shown (see Fig. 5), the reversal potentials were estimated to $E_{\text {exc }} \approx 0 \mathrm{mV}, E_{\text {inh }} \approx-81 \mathrm{mV}$, and $E_{\text {Leak }}=-79 \mathrm{mV}$ to minimize the presence of negative conductances. $E_{\text {inh }}$ was otherwise adjusted according to the action potential voltage threshold. The thresholds were determined by the first peak in the third derivative of $V_{\mathrm{m}}$ before an action potential (Henze and Buzsáki, 2001). $E_{\text {inh }}$ was then set to $-65 \mathrm{mV}$ and adjusted according to the difference between the minimum action potential threshold for the given recording and the population average $\left(E_{\text {threshold }}=-42 \mathrm{mV}\right)$.

Synaptic fluctuations. The fluctuations in $V_{\mathrm{m}}$ caused by synaptic inputs were estimated in both on and off cycles. In the on cycle, a spike-triggered value $18 \mathrm{~ms}$ before the spike occurred to diminish contamination from spikes. Multiple trials of off cycles were aligned at their center trough of $V_{\mathrm{m}}$, and a $200 \mathrm{~ms}$ window was selected for processing. The $\mathrm{SD}$ of the high-pass-filtered window was used as a measure for the synaptic fluctuations.

\section{Identification of motoneurons}

Motoneurons were mainly identified by their location in the ventral horn, size (via $R_{\mathrm{m}}$ ), and spiking relationship with nerve activity. A subset was filled with biocytin for histological processing. The tissue containing the motoneuron was carefully removed and left in PBS with $4 \%$ paraformaldehyde for 24-48 h. The tissue was then rinsed with and stored in PBS. The tissue section was mounted in an agar mount and sliced into several $100 \mu \mathrm{m}$ slices using a DSK Microslicer (model DTK-3000W). The slices were incubated for 3-4 h at room temperature with cyanine-3 conjugated to streptavidin (1:500 or 1:250; Jackson ImmunoResearch Laboratories) in blocking buffer (PBS with 5\% donkey serum and $0.3 \%$ Triton X-100). The slices were washed with PBS and incubated overnight at $5^{\circ} \mathrm{C}$ with primary choline acetyltransferase antibodies and goat antiChAT antibodies (1:500, AB144P; Millipore) diluted in blocking buffer. The slices were washed three times with PBS and incubated for $1 \mathrm{~h}$ at room temperature with the secondary antibody, Alexa488, conjugated to donkey anti-goat antibodies (1:1000; Jackson ImmunoResearch Laboratories) diluted in blocking buffer. After three washes with PBS, the slice was mounted and coverslipped using ProLong Gold antifade reagent (Invitrogen) and cured overnight at room temperature before microscopy. The slice was viewed using a confocal microscope (Zeiss LSM 700 with diode lasers) on an Axiolmager M2 using $10 \times / 0.30$ EC PlanNeofluar, $40 \times / 0.6$ Corr LD Plan-Neofluar, and $63 \times / 1.40$ oil DIC PlanApochromat objectives (Zeiss). The fluorophore Cy3 is excited at $555 \mathrm{~nm}$ and detected in the range $560-1000 \mathrm{~nm}$, whereas Alexa488 is excited at $488 \mathrm{~nm}$ and detected in the range $0-544 \mathrm{~nm}$. Images were handled with ZEN 2009 software (Zeiss) in the LSM and 8-bit TIFF format.

\section{Balanced network model}

A simple model of a balanced network (see Fig. 7) was constructed, to assess the impact of structural divisions. The model network projects to motoneurons belonging to the same nucleus. Since it is known that there are important nonlocal descending inputs (Berkowitz and Stein, 1994) with persistent and excitatory activity (Currie and Stein, 1990), we assumed that there was an external drive to the local network, which was unaffected by the transection. The local network consisted of $n$ inhibitory and $n$ excitatory neurons with random connectivity. Each neuron had, on average, $K$ inhibitory and $K$ excitatory presynaptic connections. Each neuron was modeled as a leaky integrate-and-fire neuron with $V_{\mathrm{m}}$ given by the following:

$$
C_{m} \frac{d V_{m}}{d t}=G_{L}\left(V_{\text {rest }}-V_{m}\right)+\sum_{k} I_{s y n, k},
$$

where $V_{\text {rest }}$ is the resting potential and $I_{\text {syn, } \mathrm{k}}$ is the synaptic current of the $k$ th presynaptic neuron. An action potential was produced if $V_{\mathrm{m}}$ reached threshold $V_{\mathrm{thr}} . V_{\mathrm{m}}$ was reset to $V_{\text {rest }}$ immediately after an action potential. To simplify, the variables were rescaled so that the threshold became 1 and the resting potential was 0 . The synaptic currents were modeled as doubleexponential and with a strength of $J_{k} / \sqrt{K}$ where $J_{\mathrm{k}}$ was specific for the type of connection (see below). Explicitly, $I_{s y n, k}=\frac{J_{k}}{\sqrt{K}} \frac{1}{\tau_{d}-\tau_{r}} \Sigma_{i}\left(e^{-\frac{t_{i}}{\tau_{d}}}-e^{-\frac{t_{i}}{\tau_{r}}}\right)$, where $t_{i}=t-t_{i}^{\prime}$ and $t_{i}^{\prime}$ were the time of the $i$ th presynaptic spike and $t_{\mathrm{i}}=$ 0 for $t<t_{i}^{\prime} . \tau_{\mathrm{r}}$ and $\tau_{\mathrm{d}}$ are the synaptic rise and decay time, respectively, which we set to $\tau_{\mathrm{r}}=1 \mathrm{~ms}$ and $\tau_{\mathrm{d}}=3 \mathrm{~ms}$. The external input was modeled as coming from $N_{\text {ext }}$ excitatory neurons, which were spiking with independent Poisson rates (see Fig. $7 A$ ). On average, each neuron had $K_{\text {ext }}$ presynaptic inputs from external neurons. The network was transected by removing parts of the balanced portion of the circuitry while keeping the external circuitry, the central pattern generator (CPG), and the motoneuron nucleus intact (see Fig. $7 B$ ). Some of the excitatory neurons, $N_{\text {out }, \mathrm{E}}$, and inhibitory neurons, $N_{\text {out,I }}$, projected to the motoneuron nucleus. The network was simulated by numerically integrating the differential equations with a second-order Runge-Kutta algorithm with an iteration time step of $0.1 \mathrm{~ms}$ using custom-designed $\mathrm{C}++$ procedures. All analyses of the results were performed in Matlab. Random numbers were generated with the GNU Scientific Library (http://www.gnu.org/s/gsl/), and Gaussian random numbers were generated with the Ziggurat method. The spike timings were determined by linear interpolation to increase the temporal precision (Hansel et al., 1998). The remaining parameters used in the simulation were: $N_{\text {exc }}=$ $N_{\text {inh }}=500, N_{\text {ext }}=1000, K=K_{\text {ext }}=100, \tau_{\mathrm{m}}=C_{\mathrm{m}} / G_{\mathrm{L}}, \tau_{\mathrm{m}, \mathrm{e}}=10 \mathrm{~ms}, \tau_{\mathrm{m}, \mathrm{i}}=$ $25 \mathrm{~ms}, J_{\mathrm{ee}}=1, J_{\mathrm{ie}}=1, J_{\mathrm{ei}}=-10, J_{\mathrm{ii}}=-4, J_{\mathrm{e}, \mathrm{ext}}=8$, and $J_{i, e x t}=2 . V_{\mathrm{m}}$ was normalized so $V_{\text {rest }}=0$, and the thresholds are $V_{\text {thr,e }}=1$ for excitatory and $V_{\mathrm{thr}, \mathrm{i}}=0.335$ for inhibitory neurons.

Expected behavior. The mean excitatory and inhibitory input currents to an average neuron are as follows:

$$
\begin{aligned}
I_{e} & =J_{e e} \sqrt{K} r_{e}+J_{e i} \sqrt{K} r_{i}+J_{e, e x t} \sqrt{K_{e x t}} r_{e x t}, \\
I_{i} & =J_{i e} \sqrt{K} r_{e}+J_{i i} \sqrt{K} r_{i}+J_{i, e x t} \sqrt{K_{e x t}} r_{e x t},
\end{aligned}
$$

where $r_{\mathrm{e}}, r_{\mathrm{i}}$, and $r_{\mathrm{ext}}$ are the average firing rates for the excitatory, inhibitory and the external population, respectively. For the currents not to diverge for large $K$, the terms in Eqs. 7 and 8 have to balance as follows:

$$
\begin{aligned}
& J_{e e} r_{e}+J_{e i} r_{i}+\gamma J_{e, e x t} r_{e x t}=O\left(\frac{1}{\sqrt{K}}\right), \\
& J_{i e} r_{e}+J_{i i} r_{i}+\gamma J_{i, e x t} r_{e x t}=O\left(\frac{1}{\sqrt{K}}\right),
\end{aligned}
$$

where $\sqrt{K_{\text {ext }}}=\gamma \sqrt{K}$ and $\gamma$ is a finite fraction of the external to the internal connections; in our case, $\gamma=1$. The average rates for the $\mathrm{E}$ and the I populations can then be approximated as follows:

$$
\begin{aligned}
& r_{e} \approx \frac{J_{i j} J_{e, e x t}-J_{e j} J_{i, e x t}}{J_{e j} J_{i e}-J_{e e} J_{i i}} \sqrt{\frac{K_{e x t}}{K}} r_{e x t} \\
& r_{i} \approx \frac{J_{e e} J_{i, e x t}-J_{i e} J_{e, e x t}}{J_{e j} J_{i e}-J_{e e} J_{i i}} \sqrt{\frac{K_{e x t}}{K}} r_{e x t} .
\end{aligned}
$$

Both rates are proportional to the external rate and independent on the number of neurons. When transecting the network and reducing the network size to a fraction $\alpha$, the number of presynaptic inputs to an average neuron will decrease to $K=\alpha K^{\prime}$, where $K^{\prime}$ is the original input to an average neuron. Since $K_{\text {ext }}$ remains the same, we arrive at the coun- 
terintuitive result that a structural division will cause higher spike rates of the remaining neurons. The rates are increased by approximately $1 / \sqrt{\alpha}$, which is fairly small for reasonable divisions, i.e., $<50 \%$, suggesting that the dynamics of a balanced network is quite resilient to structural divisions.

\section{Results}

Concurrence between excitation and inhibition of hip flexor motoneurons was found in a previous study where the spinal cord was transected at D10 (Berg et al., 2007). This study implemented the ohmic analysis to extract synaptic conductances from multiple trial data (Fig. $2 A-D$ ). The synaptic input was characterized by having a large rhythmic conductance, both for inhibition and excitation with high concurrence, in qualitative agreement with the balanced scheme (Fig. 1E). We repeated this analysis for cells in the intact cord. The analysis was augmented by an additional method of estimating synaptic conductances, the ACF method, which does not require multiple trial data (Fig. $2 E, F)$. First, we performed a basic comparison between the activity in the intact and the transected spinal cord to determine the impact of the transection.

\section{Transection}

Impact on motor behavior

The activity of four motor nerves from the lumbar spinal cord enlargement (Fig. $3 A)$ in turtles $(n=3)$ was recorded during tactile induced pocket scratch activity in the intact condition (Fig. $3 B$ ). Next, the spinal cord was carefully transected at the border of D10, and the motor activity was observed in response to the same tactile activated pocket scratch (Fig. 3C). The nerve activity of $\mathrm{dD} 8$ (Fig. $3 C$, top trace), the hip flexor (Fig. 3C, top middle), and the knee extensor (Fig. 3C, bottom middle) had little or no qualitative change in amplitude and cycle period after the transection. The hip extensor nerve (Fig. 3C, bottom trace) was severely affected by the transection, which is likely caused by the more caudal location (Fig. 3, compare $B, C$ ). The nerve activities were quantified as the normalized ENG spectral power, which had a gradual decrease from trial to trial before transection (Fig. 3D, cyan columns). After transection, the activity level declined, though both hip flexor and knee extensors had a transient increase in power (Fig. 3D, magenta columns). The average normalized power was not significantly affected (Fig. 3E). The respective phase relationships between the nerves were quantified via the coherence function, and these were not significantly affected by the transection (Fig. $3 F$ ).

\section{Synaptic fluctuations}

We compared the synaptic fluctuating potentials in neurons in the intact and transected spinal cord (Fig. 4) and separated the motor behavior into on and off cycles (Fig. $4 A$ ). Since the on cycles often have high spike density, we estimated the fluctuation via the $\mathrm{SD}$ of the spike-triggered distribution of $V_{\mathrm{m}}$ before the peak of the action potential (Fig. 4B). Fluctuations in the off
B C
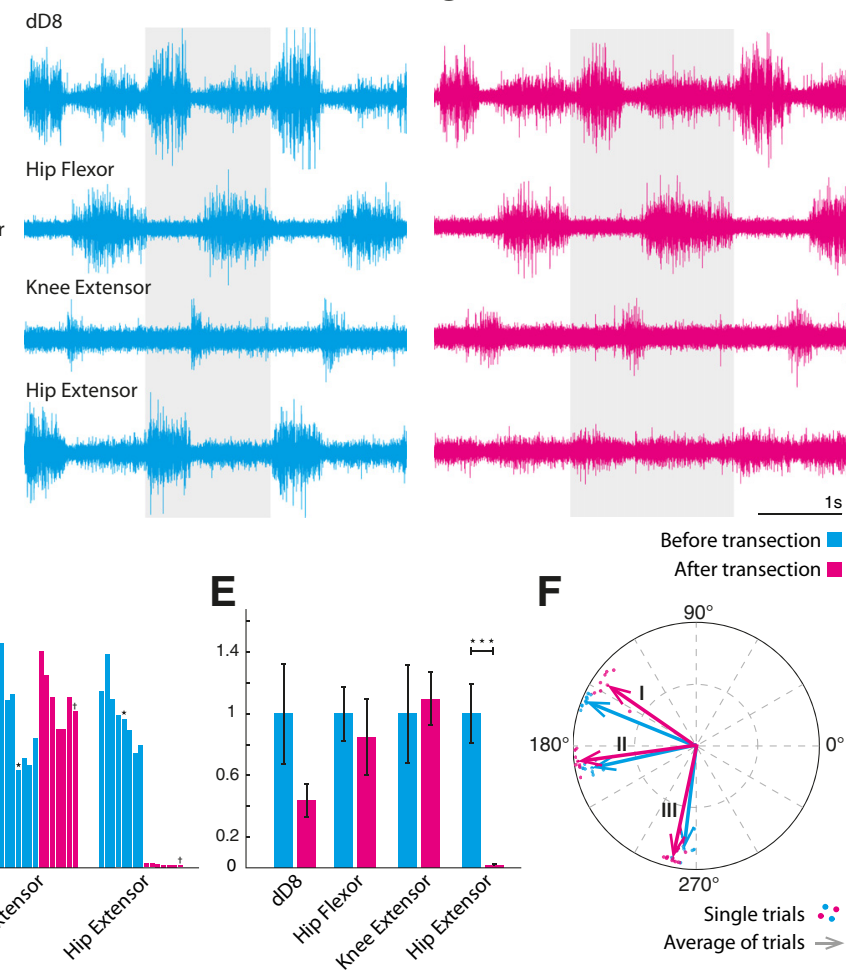

$\mathbf{F}$

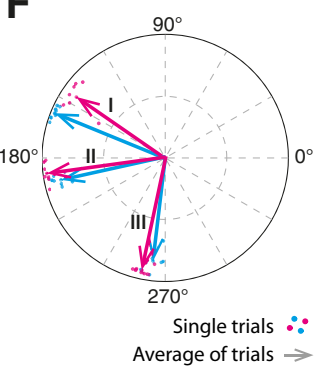

Figure 3. A caudal transection has marginal effects on motor activity. $\boldsymbol{A}$, Lumbar enlargement of the turtle spinal cord. Spinal segments and nerves are labeled. The transection is performed at the caudal end of segment D10 (dashed line), to allow access to in $\boldsymbol{D}$. Significant difference is indicated $(\star \star \star)$. $\boldsymbol{F}$, Coherence between three nerve pairs (I, hip flexor vs extensor; II, dD8 vs hip flexor; III, hip flexor vs knee extensor) at the dominant frequency. Dots indicate single trials, and arrows indicate trial average.

cycles were determined as the SD of $V_{\mathrm{m}}$ over time (Fig. $4 C$ ). The distributions of synaptic fluctuations did not show a significant difference between the intact spinal cord and the transected spinal cord neither during the on-cycle periods (Fig. 4D) nor during the off-cycle periods (Fig. 4E).

\section{Excitation and inhibition to motoneurons}

We analyzed intracellular recordings from neurons in the transected (Fig. 2) and the intact (Figs. 5, 6) spinal cord to estimate E and I conductances during motor patterns. The synaptic inputs were estimated using both the ohmic and the ACF methods on data for which these methods were suitable (Berg and Ditlevsen, 2013). Motoneurons were identified according to their spiking activity with respect to the nerve activity (Fig. 5A) and their anatomical location (Fig. 5E). Sample estimates of $G_{\text {inh }}$ and $G_{\text {exc }}$ using the ACF method on single sweep data (Fig. $5 B, C$ ) had a significant correlation (Fig. 5D). The majority of cells in the population showed a similar positive correlation between $G_{i n h}$ and $G_{\text {exc }}$, although two cells showed a mild negative correlation (Fig. $6 A$ ). A sample experiment and estimates from one of these two cells is shown (Fig. $6 B-D$ ). Excitation is weak and in opposite phase with inhibition. The spike rate is low, and $G_{\text {tot }}$ is strongest in the off cycles, which was atypical for the population.

\section{Structural division in a balanced network model}

Since the experiments demonstrated mainly balanced E/I and resemblance between intact and transected spinal cord, it is rele- 

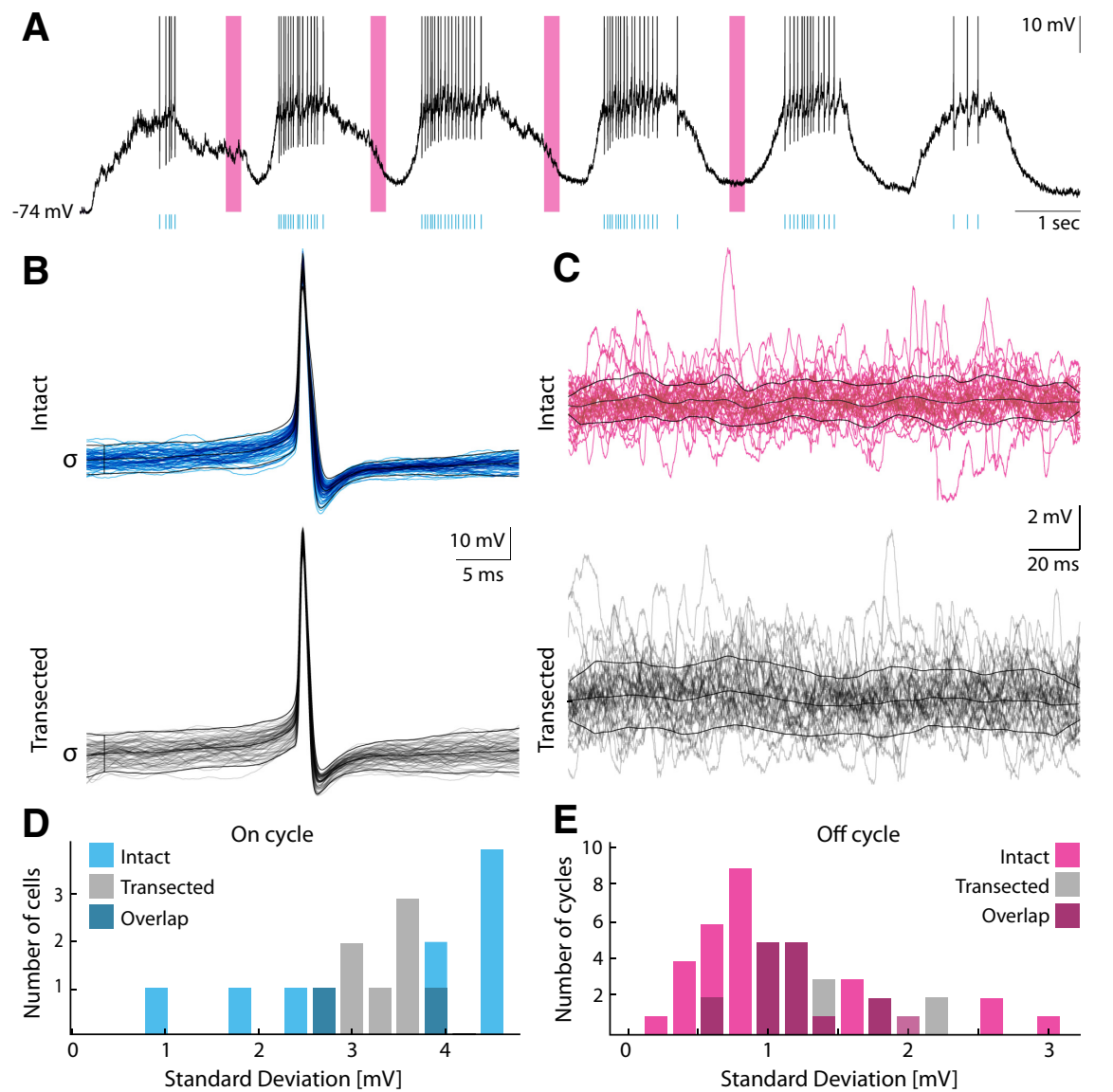

Figure 4. Synaptic fluctuations in motoneurons are unaffected by transection. $\boldsymbol{A}$, Membrane potential from a sample neuron during a scratch reflex $\left(I_{\text {inj }}=0\right)$. Spike times are indicated by cyan vertical lines. Selected off cycles are indicated by magenta bars. $\boldsymbol{B}$, Synaptic fluctuations in on cycles are assessed as the trial variance of $V_{m^{\prime}}, 18$ ms before the triggered spikes (Berg et al., 2008), for intact (cyan) and transected (gray). C, Synaptic fluctuations in off cycles are assessed as SDs in $200 \mathrm{~ms}$ windows of $V_{\mathrm{m}}$ across time and cycles. $\boldsymbol{D}, \boldsymbol{E}$, Population distribution of synaptic fluctuations in intact ( $n=10$ cells) and transected ( $n=8$ cells) for the on cycle $($ cyan, $\boldsymbol{D})$ and off cycle (magenta, $\boldsymbol{E}$ ). Intact and transected populations are statistically indistinguishable in on cycles and in off cycles, using a Kolmogorov-Smirnov two-sample test ( $\alpha=5 \%$ ).

vant to consider the impact of structural divisions in a balanced network. We therefore constructed a simple model of the premotor network consisting of two populations of $\mathrm{E}$ and I neurons (Fig. 7A), with fixed random connectivity (van Vreeswijk and Sompolinsky, 1996; Brunel, 2000). What happens to the dynamics when the network is reduced to a fraction, $\alpha$, such that the motoneurons receive inputs from fewer premotor neurons (Fig. $7 B$ )? First, we noticed that the average firing rate of inhibitory neurons (Fig. $7 C$, red) was lower than the excitatory neurons (Fig. $7 C$, blue) and that their spiking was irregular (Fig. 7C, left). The irregular spiking was expected since it is a hallmark of balanced networks in the asynchronous state (Vogels et al., 2005). The lower firing rate of the inhibitory population was attributable to the choice of connection strengths and the balancing condition that recurrent inhibition has to dominate recurrent excitation to maintain stability, which lead to explicit expressions of rates (Eqs. 9, 10).

A structural division will decrease the number of neurons, which should have little or no effect on the firing rates (Eqs. 9, 10). Nevertheless, there was a slight increase in the mean firing rate for both $\mathrm{E}$ and I neurons after transection (Fig. 7C). This was not caused by the reduction of the population directly, but rather by the elimination of some of the recurrent connections. The average number of presynaptic inputs to a neuron was diminished by $\alpha$, such that $K=\alpha K^{\prime}$, where $K^{\prime}$ is the original input to an average neuron. This will increase the mean firing rates after the division since they are proportional to $1 / \sqrt{\alpha}$ and $0<$ $\alpha<1$ (Eqs. 9, 10). Furthermore, there was a linear relationship between the external input rate and the mean firing rate of both $\mathrm{E}$ and I, again with an increase after the transection (Fig. 7D).

Despite increasing firing rates for the remaining premotor neurons, the synaptic inputs to motoneurons will decrease because of the decreasing number of presynaptic cells after the division. Consequently, the higher average firing rate of the active neurons was counterbalanced by fewer active connections to motoneurons, and therefore we saw only a small effect on the motoneuron activity (Fig. $7 E$ ). Interestingly, the structural division of the network did not alter the balanced state. After transection of the spinal cord, the activity of $\mathrm{E}$ neurons still remained in proportion to I neurons (Fig. 7F). These observations are in qualitative accordance with the experimental observations: there was very little change in the ENG amplitude, i.e., the mean motoneuron input after transection (Fig. 3), the inputs to motoneurons were still balanced E/I (Figs. 5, 6), and the activity was still irregular (Fig. 4).

\section{Discussion}

In the present study, we investigated the sensitivity of the functional network integrity to a structural division at the D9/ D10 segment in the turtle spinal cord. The study can be summarized into the following observations. First, there was no significant change in the ENG amplitudes after the transection (Fig. 3B-E). This suggests that the motoneurons had the same levels of activity and therefore received similar amounts of E/I input before and after the structural division. Second, the relative timing of synergists/ antagonists seemed to be unaffected by the transection (Fig. $3 F$ ), which indicates the disconnected network could not have served a vital purpose for the network integrity. Third, the synaptic fluctuations were qualitatively similar before and after transection in both on and off cycles (Fig. 4B-E). This suggests that there was no substantial change in the amounts of synaptic inhibition and/or excitation in both phases. Fourth, waves of excitation and inhibition were qualitatively similar in intact versus transected spinal cord. The synaptic motoneuron inputs were balanced in most cells $(n=13$ of 15$)$, although two cells had stronger off-cycle inhibition (Figs. 5, 6). The balanced activity of the premotor network and its resilience to structural division is in accordance with the proposed model (Fig. 7), which also remained balanced after the transection (Fig. $7 F$ ). These results lend support to a premotor network with recurrent E/I circuitry, which has a remarkable ability to preserve functional integrity.

\section{Resolving discrepancies between turtle and rat}

Our data are at odds with the observation by Endo and Kiehn (2008) that locomotion in rats is mainly controlled by recip- 

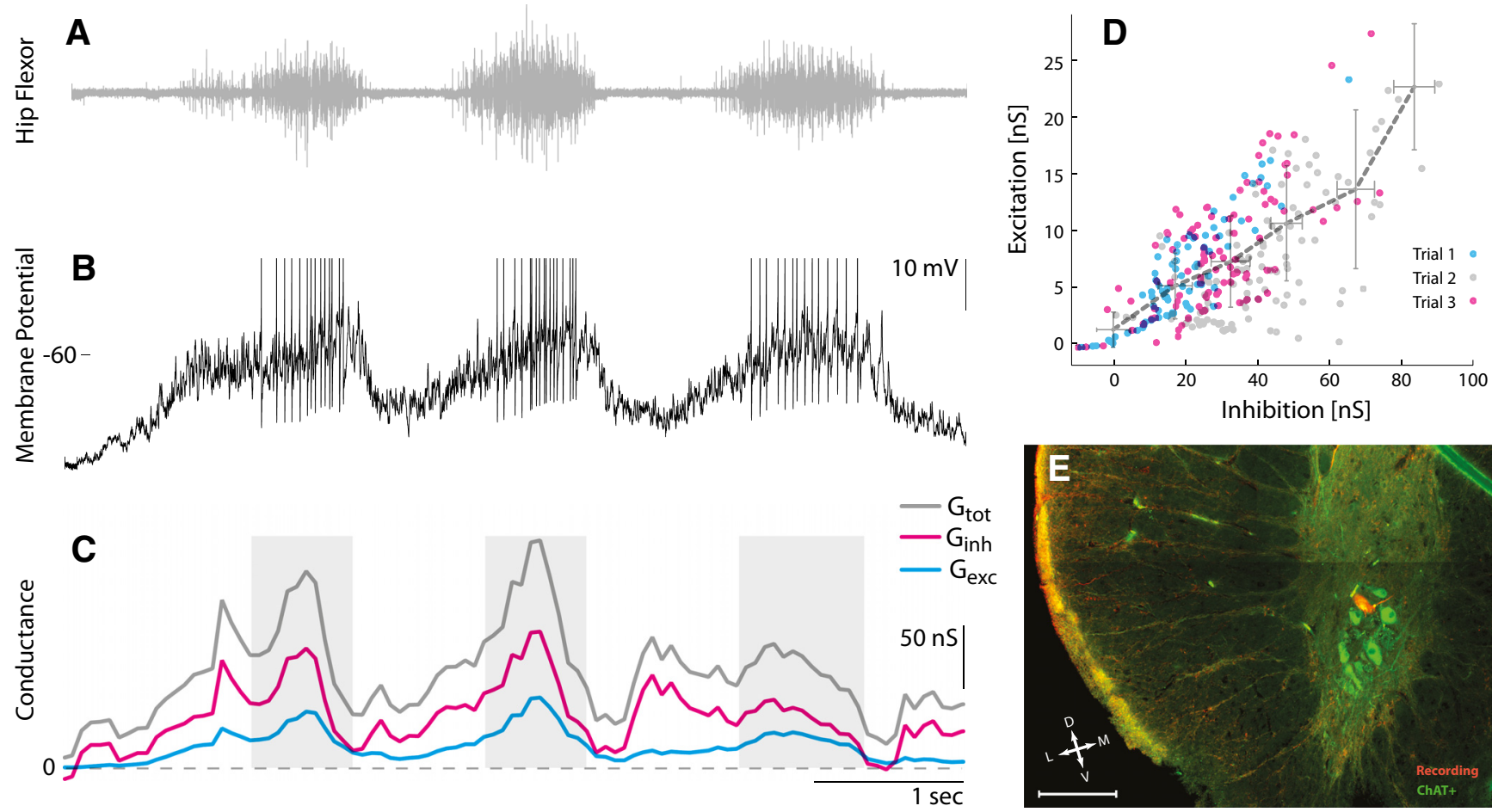

Figure 5. Sample motoneuron in D10 from an intact spinal cord receiving balanced synaptic input. $A$, Hip flexor nerve recording during tactile induced pocket scratching. $B, V_{\mathrm{m}}$ during constant current injection $\left(I_{\text {inj }}=0\right.$ ). Action potentials clipped at $-40 \mathrm{mV}$. C, The total conductance (gray), inhibition (magenta), and excitation (cyan) estimated with the ACF method using a $250 \mathrm{~ms}$ window. Shaded regions indicate the location for which the windows contained spikes. $\boldsymbol{D}$, Inhibition and excitation estimated with the ACF method without spikes for three trials. The gray dashed line connects the $x$ - $y$ averages in six bins on the abscissa. Error bars indicate their respective SD. $E$, Transverse histological section to confirm the biocytin-filled neuron (red) used in $\boldsymbol{A}-\boldsymbol{D}$ belongs to the group of motoneurons in the ventral horn (ChAT-positive neurons shown in green). Scale bar, $200 \mu \mathrm{m}$.

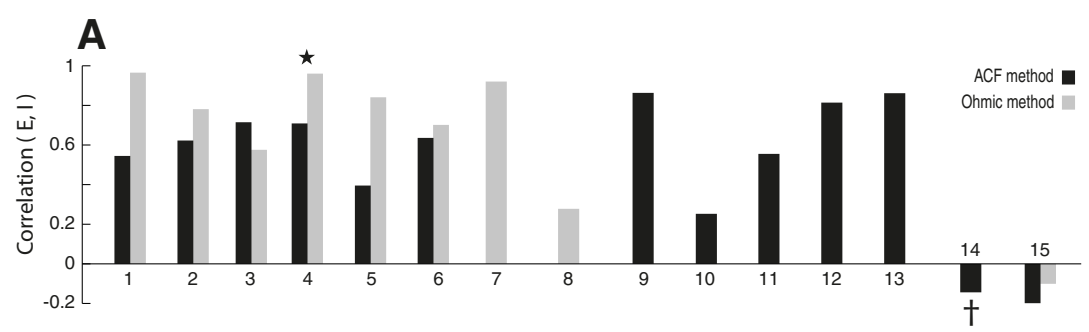

B
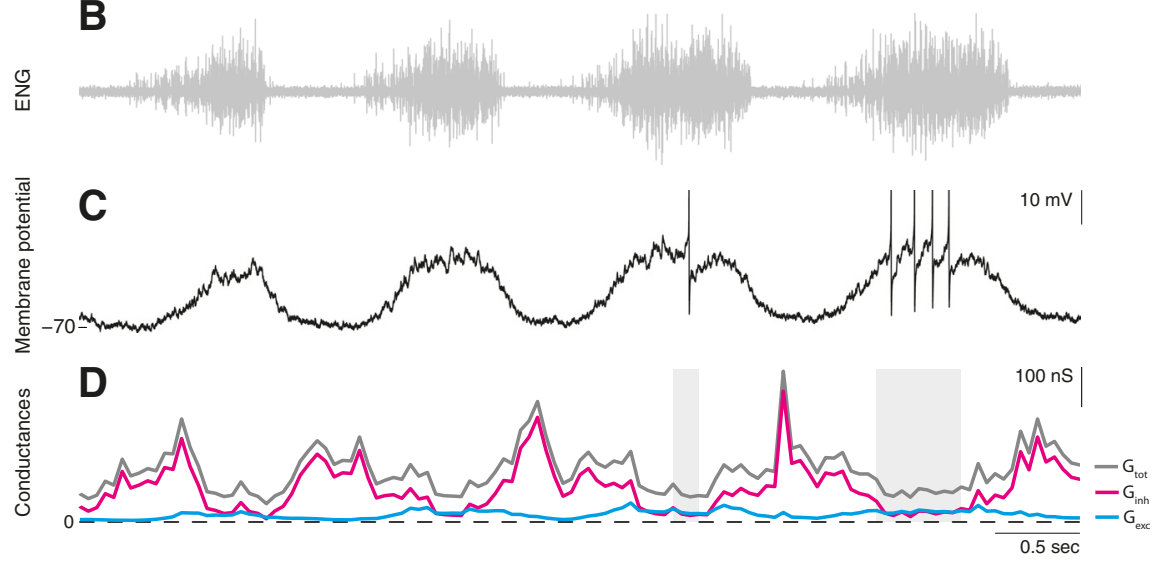

Figure 6. Balanced $\mathrm{E} / \mathrm{I}$ in the majority of cells, with the exception of two cells. $\boldsymbol{A}$, The correlation between excitation and inhibition for a population of neurons $(n=15)$, estimated via the ACF method (black) and ohmic method (gray). Most cells ( $n=$ 13) have a positive correlation between $E$ and $I$, with the exception of two cells. A sample cell from Figure 5 is indicated by a star. $\boldsymbol{B}-\boldsymbol{D}$, Sample neuron receiving opposite timing of $\mathrm{E}$ and $\mathbf{I}$. $\boldsymbol{B}$, Flexor nerve recording. $\boldsymbol{C}$, Membrane potential $\left(\boldsymbol{I}_{\text {inj }}=0\right)$ of sample neuron $14(\dagger)$. Action potentials clipped at $-30 \mathrm{mV}$. D, The total conductance (gray), inhibition (magenta), and excitation (cyan) estimated with the ACF method using a $200 \mathrm{~ms}$ window. Shaded regions indicate the omitted locations in which the windows contained spikes. rocal inhibition with little or no excitation, which was confirmed in mice (Talpalar et al., 2011). There are a number of different possibilities for the discrepancy between the results. The premotor networks controlling scratching and locomotion could have different specialization as proposed for cats (Frigon and Gossard, 2010), or there could be a species difference. Alternatively, differences between rodents and turtles could be explained by differences in the precision of the movements that relate to developmental stage: neonatal for rodents and adult for turtles. For instance, in movements where the control of force is critical, such as the precision grip tasks in monkeys, there is coactivation between E/I premotoneurons (Takei and Seki, 2013; Wu and Perlmutter, 2013). Furthermore, inhibition has an important role in adjusting force during hindlimb control in adult cats (Johnson et al., 2012), suggesting that the degree of balance E/I depends on the particular task and force. Neonatal/embryonic rodents performing fictive locomotion are unable to carry themselves and therefore unable to adjust force appropriately. This motor inability is linked to immaturity of the spinal motor network and therefore could explain the discrepancy be- 
A

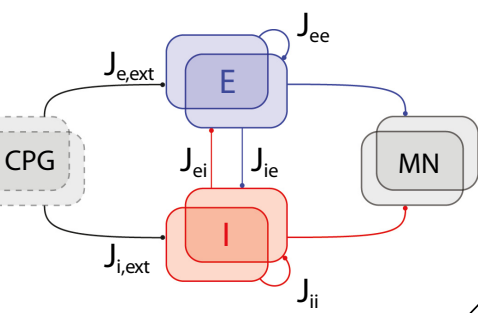

B

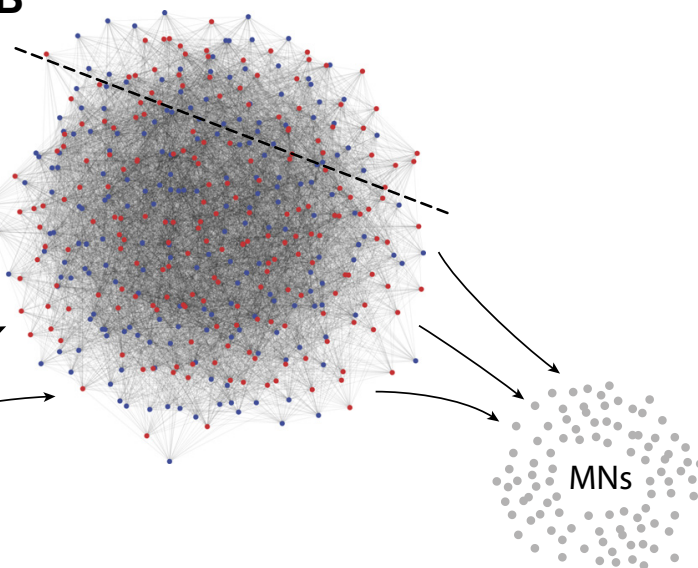

C

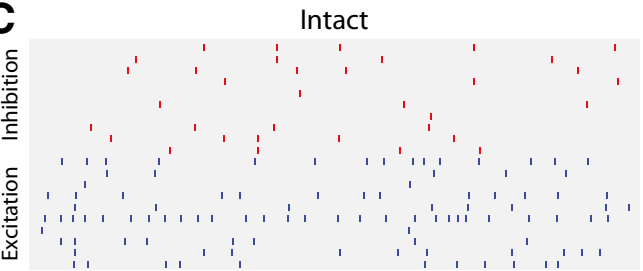

Transected

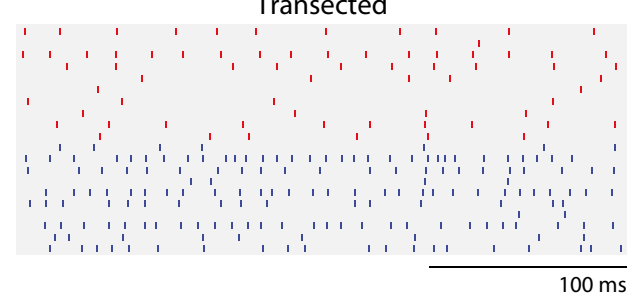

D

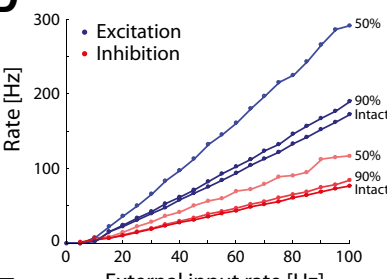

E

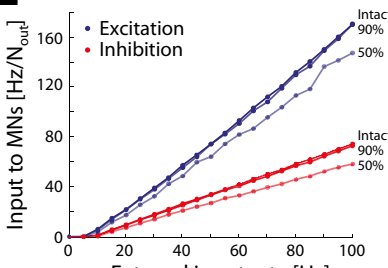

$\mathbf{F}$

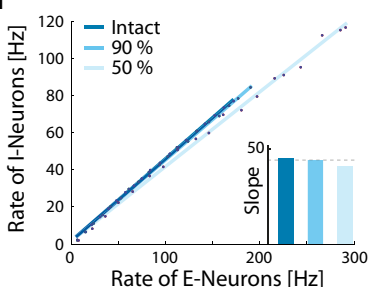

Figure 7. The model network remains balanced after structural division. A, Schematic of the architecture of the local network. Input is provided by an external population of excitatory neurons $(\mathrm{CPG})$, which connects to both the excitatory (blue boxes) and inhibitory (red boxes) populations. Subsets of these populations project to each other resulting in recurrent inhibition and excitation. Other subsets of E/I project to motoneurons (MN; right gray box). $B$, Detailed schematic of a miniature premotor network consisting of inhibitory (red; $\left.N_{\text {inh }}=100\right)$ and excitatory (blue; $N_{\text {exc }}=100$ ) neurons. A subset of the population receives excitatory inputs from the external source (CPG; left gray cells), and another subset projects to local motoneurons (bottom right gray cells). A transection line is indicated with a dashed line. C, Rastergram of 10 sample neurons of both $E$ and I populations before and after transection (50\%). $\boldsymbol{D}$, The mean spike rates of $\mathrm{E}$ (blue) and I (red) for the intact, 10 and $50 \%$ transected network as a function of external drive. $E$, The $E$ (blue) and I (red) spike rate input to a sample motoneuron normalized by the total number of output projections $\left(N_{\text {out }, I}\right.$ and $N_{\text {out.E }}$ ) as a function of external input to the premotor network for intact, $10 \%$ and $50 \%$ transected network. $F$, The mean rates of Eversus I neurons for intact and transected premotor network, and their slopes have marginal change after transection (inset).
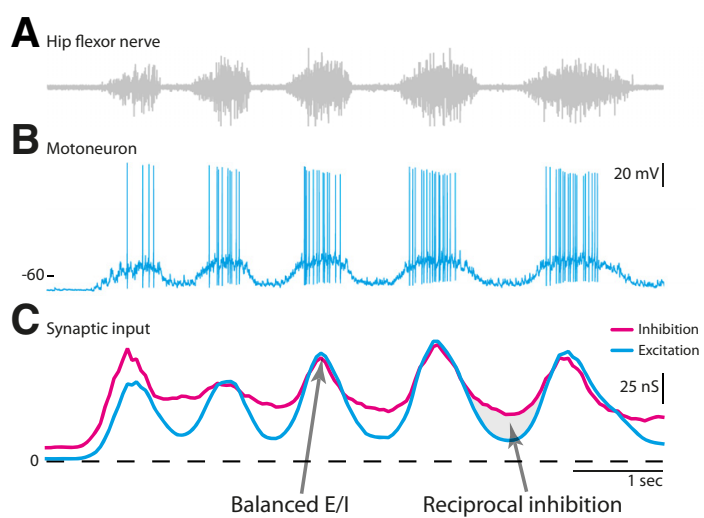

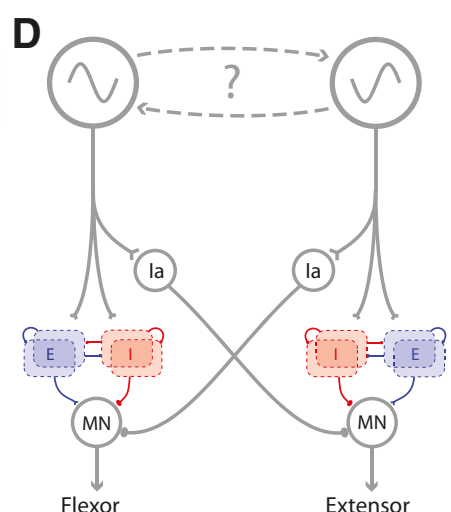

Figure 8. Sample data and proposed model for motor circuitry. $A, B$, Tactile induced motor behavior consisting of coordinated rhythmic muscle contractions $(\boldsymbol{A})$ and depolarizations in the membrane potential of the corresponding motoneuron $(\boldsymbol{B})$. $\boldsymbol{C}$, The rhythmic behavior is caused by waves of inhibition (magenta) and excitation (cyan) to the motoneuron. In the on cycles, excitation and inhibition are concurrently peaking, hence the motoneuron is receiving balanced input from the premotor network (arrow), whereas in the off cycles, there is relatively more inhibition than excitation, which is likely caused by the activation of reciprocal inhibition from the antagonist (arrow and shaded region). Data are adapted from Berg and Ditlevsen (2013) with permission. D, The proposed model: descending inputs from a rhythm-generating network provides drive to both a premotor network, where recurrent excitation (blue population) is balanced with recurrent inhibition (red population), as well as generic reciprocal inhibitory interneurons. The connectivity and number of $\mathrm{E} / \mathrm{I}$ neurons in the network is unknown. MN, Motoneuron; la, reciprocal inhibitory premotor interneuron.

tween the results obtained from adult turtles and neonatal rats. The importance of the developmental stage in forming a balanced network is seen in other parts of the nervous system. For instance, the auditory cortex is known to have balanced
$\mathrm{E} / \mathrm{I}$ in the adult rat (Wehr and Zador, 2003), but in early development, the network organization is qualitatively different. The balance only becomes significant between P15 and P25 and is fully developed at P30 (Dorrn et al., 2010). Since the rats used by Endo and Kiehn (2008) were newborn (P0-P04), they are substantially younger than the point at which they develop balanced $\mathrm{E} / \mathrm{I}$ in the cortex.

Even if an $\mathrm{E} / \mathrm{I}$ balance is present in the immature spinal circuit, resolving the synaptic conductances is difficult in these experiments, because (1) the estimation of synaptic conductance is distorted by the applied neurochemicals (NMDA/5HT/dopamine) that chronically affect the receptors and (2) gap-junction couplings are present at this developmental stage. Gap junctions are important in circuitry formation and biochemical signaling, but since their abundance decreases with development (Chang and Balice-Gordon, 2000), they are probably less important in adult locomotion. Nevertheless, they have a tremendous impact on the electrical dynamics associated with neonatal fictive locomotion. For instance, rhythmic motor patterns can be communicated purely through electrical coupling without action 
potentials (Tresch and Kiehn, 2000). This electrical communication also distorts the estimation of synaptic conductance, which relies entirely on chemical neurotransmission (Berg and Ditlevsen, 2013).

\section{Other work in turtle}

The results from the transection experiments presented here (Fig. 3 ) are in accord with the early transection experiments by Mortin and Stein (1989). They demonstrated that the posterior $40-80 \%$ of the hindlimb enlargement is not essential for both rostral and pocket scratch generation. Currie and Gonsalves (1999) performed similar transection experiments, indicating that at least some of D10 is required to have on/off phase separation in the unilateral rhythm. Since our ENG recordings have clear on/off separation (Fig. $3 C$ ), the transection must have been more caudal than those performed by Currie and Gonsalves (1999). Nevertheless, the essential signals for motor pattern activation are carried by descending fibers (Berkowitz and Stein, 1994).

In their seminal work, Robertson and Stein (1988) performed a comprehensive assessment of the synaptic input during the off cycles in the key synergist and antagonist motoneurons. Though their work confirmed the presence of off-cycle inhibition, the authors did not consider on-cycle inhibition, perhaps because of their awareness of the absence of Renshaw inhibition (Ruigrok et al., 1984). Nevertheless, using the ohmic method on their trials with different current injections [Robertson and Stein (1988), their Fig. 3], we are able to corroborate the existence of an inhibitory on-cycle component (data not shown). The authors also manipulated the chloride reversal potential, which broadened the on cycle. This is likely attributable to a general broader inhibition and sharper excitation (Figs. 2C, 5C). Based on this metaanalysis, we suggest that there is a qualitative accord between past and present data.

\section{Purpose of balanced input to motoneurons}

We investigated inputs to hip flexor motoneurons, whereas the hip extensor motoneuron inputs are yet unresolved. A possible discrepancy between inputs to flexor and extensor motoneurons could be related to the particular motor behavior, which in this case is pocket scratching (Earhart and Stein, 2000). In this type of scratching, the knee is moved forward to rub against the location in the receptive field where the tactile stimulus occurred. Therefore, in this part of the cycle, referred to as the rub phase (Mortin et al., 1985), the hip flexors have to exert a force of high amplitude and precision, whereas the hip extensors are active in the postrub phase, which serves only to retract the limb without a well defined target. The movement in the postrub phase has high variability, whereas the rub phase has low variability (Mortin et al., 1985). This need for finer motor control makes it necessary for the premotor network to have accurate control of the hip flexor motoneurons, including their gain. Suitable gain modulation of neurons can be accomplished by balancing synaptic E/I (Silver, 2010), thus offering an explanation for the balanced input, and a prediction that hip extensors receive less balanced E/I, since their control is less critical. Similarly, balanced E/I has been observed among spinal premotor interneurons during precision grip tasks by monkey, where fine motor control is required (Takei and Seki, 2013; Wu and Perlmutter, 2013).

\section{Premotor network architecture}

The participating interneurons in spinal premotor networks are large in numbers and scattered across multiple segments (Stepien et al., 2010). The number of synaptic contacts onto a motoneuron can be up to 60,000 (Ulfhake and Cullheim, 1988), and motoneurons often exhibit irregular activity suggesting intense synaptic bombardment (Calvin and Stevens, 1967; Berg et al., 2008; Jahn et al., 2011; Dideriksen et al., 2012). There are eight interneurons for every motoneuron in the turtle spinal segment D9, and the number is similarly high in the lumbar enlargement in chickens (6:1) and mice (15:1) (Walløe et al., 2011). The relative high number of interneurons implies a more complicated architecture than the pure feedforward half-center model. If all neurons were feedforward connected, the signal propagation would either be slow, because of the vast number of intermediate neurons, or highly redundant through parallel connections. Alternatively, the large number of interneurons could constitute recurrent connectivity, which would provide higher processing capabilities. A balanced recurrent network has the potential of exhibiting a rich repertoire of dynamical states (Shu et al., 2003) and could therefore offer a novel direction in investigating the flexibility and multifunctionalism of motor networks (Berkowitz et al., 2010; Berkowitz and Hao, 2011). Nevertheless, recurrent excitatory connections will tend to make networks unstable (Vogels et al., 2005), and a dominant recurrent inhibition is therefore required (Brunel, 2000). Reciprocal connections will not stabilize the activity as they only give off-cycle inhibition.

Based on these observations, we propose a minimalistic model (Fig. 8). The model is composed of the generic reciprocal inhibition combined with a locally balanced premotor network (Stein, 2010), both receiving descending connections from a rhythmgenerating network.

\section{References}

Alaburda A, Hounsgaard J (2003) Metabotropic modulation of motoneurons by scratch-like spinal network activity. J Neurosci 23:8625-8629. Medline

Alaburda A, Russo R, MacAulay N, Hounsgaard J (2005) Periodic highconductance states in spinal neurons during scratch-like network activity in adult turtles. J Neurosci 25:6316-6321. CrossRef Medline

Anderson JS, Carandini M, Ferster D (2000) Orientation tuning of input conductance, excitation, and inhibition in cat primary visual cortex. J Neurophysiol 84:909-926. Medline

Atallah BV, Scanziani M (2009) Instantaneous modulation of gamma oscillation frequency by balancing excitation with inhibition. Neuron 62:566577. CrossRef Medline

Baca SM, Marin-Burgin A, Wagenaar DA, Kristan WB Jr (2008) Widespread inhibition proportional to excitation controls the gain of a leech behavioral circuit. Neuron 57:276-289. CrossRef Medline

Berg RW, Ditlevsen S (2013) Synaptic inhibition and excitation estimated via the time constant of membrane potential fluctuations. J Neurophysiol 110:1021-1034. CrossRef Medline

Berg RW, Alaburda A, Hounsgaard J (2007) Balanced inhibition and excitation drive spike activity in spinal half-centers. Science 315:390-393. CrossRef Medline

Berg RW, Ditlevsen S, Hounsgaard J (2008) Intense synaptic activity enhances temporal resolution in spinal motoneurons. PLoS One 3:e3218. CrossRef Medline

Berkowitz A, Hao Z-Z (2011) Partly shared spinal cord networks for locomotion and scratching. Integr Comp Biol 51:890-902. CrossRef Medline

Berkowitz A, Stein PS (1994) Activity of descending propriospinal axons in the turtle hindlimb enlargement during two forms of fictive scratching: broad tuning to regions of the body surface. J Neurosci 14:5089-5104. Medline

Berkowitz A, Roberts A, Soffe SR (2010) Roles for multifunctional and specialized spinal interneurons during motor pattern generation in tadpoles, zebrafish larvae, and turtles. Front Behav Neurosci 4:36. CrossRef Medline

Borg-Graham LJ, Monier C, Frégnac Y (1998) Visual input evokes transient and strong shunting inhibition in visual cortical neurons. Nature 393: 369-373. CrossRef Medline

Brunel N (2000) Dynamics of sparsely connected networks of excitatory 
and inhibitory spiking neurons. J Comput Neurosci 8:183-208. CrossRef Medline

Calvin WH, Stevens CF (1967) Synaptic noise as a source of variability in the interval between action potentials. Science 155:842-844. CrossRef Medline

Cangiano L, Grillner S (2005) Mechanisms of rhythm generation in a spinal locomotor network deprived of crossed connections: the lamprey hemicord. J Neurosci 25:923-935. CrossRef Medline

Cazalets JR, Borde M, Clarac F (1996) The synaptic drive from the spinal locomotor network to motoneurons in the newborn rat. J Neurosci 16: 298-306. Medline

Chang Q, Balice-Gordon RJ (2000) Gap junctional communication among developing and injured motor neurons. Brain Res Rev 32:242-249. CrossRef Medline

Csicsvari J, Hirase H, Czurkó A, Mamiya A, Buzsáki G (1999) Oscillatory coupling of hippocampal pyramidal cells and interneurons in the behaving rat. J Neurosci 19:274-287. Medline

Currie SN, Gonsalves GG (1999) Reciprocal interactions in the turtle hindlimb enlargement contribute to scratch rhythmogenesis. J Neurophysiol 81:2977-2987. Medline

Currie SN, Stein PS (1990) Cutaneous stimulation evokes long-lasting excitation of spinal interneurons in the turtle. J Neurophysiol 64:1134-1148. Medline

de Almeida AT, Kirkwood PA (2010) Multiple phases of excitation and inhibition in central respiratory drive potentials of thoracic motoneurones in the rat. J Physiol 588:2731-2744. CrossRef Medline

Destexhe A, Rudolph M, Paré D (2003) The high-conductance state of neocortical neurons in vivo. Nat Rev Neurosci 4:739-751. CrossRef Medline

Dideriksen JL, Negro F, Enoka RM, Farina D (2012) Motor unit recruitment strategies and muscle properties determine the influence of synaptic noise on force steadiness. J Neurophysiol 107:3357-3369. CrossRef Medline

Dorrn AL, Yuan K, Barker AJ, Schreiner CE, Froemke RC (2010) Developmental sensory experience balances cortical excitation and inhibition. Nature 465:932-936. CrossRef Medline

Earhart GM, Stein PS (2000) Step, swim, and scratch motor patterns in the turtle. J Neurophysiol 84:2181-2190. Medline

Endo T, Kiehn O (2008) Asymmetric operation of the locomotor central pattern generator in the neonatal mouse spinal cord. J Neurophysiol 100: 3043-3054. CrossRef Medline

Frigon A, Gossard JP (2010) Evidence for specialized rhythm-generating mechanisms in the adult mammalian spinal cord. J Neurosci 30:70617071. CrossRef Medline

Gabriel JP, Mahmood R, Kyriakatos A, Söll I, Hauptmann G, Calabrese RL, El Manira A (2009) Serotonergic modulation of locomotion in zebrafish: endogenous release and synaptic mechanisms. J Neurosci 29:1038710395. CrossRef Medline

Geertsen SS, Stecina K, Meehan CF, Nielsen JB, Hultborn H (2011) Reciprocal Ia inhibition contributes to motoneuronal hyperpolarisation during the inactive phase of locomotion and scratching in the cat. J Physiol 589:119-134. CrossRef Medline

Graham Brown T (1924) Studies in the physiology of the nervous system. XXVIII. Absence of algebraic equility between the magnitudes of central excitation and effective central inhibition given in the reflex centre of a single limb by the same reflex stimulus. Q J Exp Physiol 14:1-23.

Grillner S (2006) Biological pattern generation: the cellular and computational logic of networks in motion. Neuron 52:751-766. CrossRef Medline

Grillner S, Jessell TM (2009) Measured motion: searching for simplicity in spinal locomotor networks. Curr Opin Neurobiol 19:572-586. CrossRef Medline

Haider B, Duque A, Hasenstaub AR, McCormick DA (2006) Neocortical network activity in vivo is generated through a dynamic balance of excitation and inhibition. J Neurosci 26:4535-4545. CrossRef Medline

Hansel D, Mato G, Meunier C, Neltner L (1998) On numerical simulations of integrate-and-fire neural networks. Neural Comput 10:467-483. CrossRef Medline

Henze DA, Buzsáki G (2001) Action potential threshold of hippocampal pyramidal cells in vivo is increased by recent spiking activity. Neuroscience 105:121-130. CrossRef Medline

Hochman S, Schmidt BJ (1998) Whole cell recordings of lumbar motoneu- rons during locomotor-like activity in the in vitro neonatal rat spinal cord. J Neurophysiol 79:743-752. Medline

Jahn P, Berg RW, Hounsgaard J, Ditlevsen S (2011) Motoneuron membrane potentials follow a time inhomogeneous jump diffusion process. J Comput Neurosci 31:563-579. CrossRef Medline

Jankowska E, Jukes MG, Lund S, Lundberg A (1965) Reciprocal innervation through interneuronal inhibition. Nature 206:198-199. CrossRef Medline

Johnson MD, Hyngstrom AS, Manuel M, Heckman CJ (2012) Push-pull control of motor output. J Neurosci 32:4592-4599. CrossRef Medline

Kolind J, Hounsgaard JR, Berg RW (2012) Opposing effects of intrinsic conductance and correlated synaptic input on Vm-fluctuations during network activity. Front Comput Neurosci 6:40. CrossRef Medline

Magnusson AK, Park TJ, Pecka M, Grothe B, Koch U (2008) Retrograde GABA signaling adjusts sound localization by balancing excitation and inhibition in the brainstem. Neuron 59:125-137. CrossRef Medline

Mariño J, Schummers J, Lyon DC, Schwabe L, Beck O, Wiesing P, Obermayer K, Sur M (2005) Invariant computations in local cortical networks with balanced excitation and inhibition. Nat Neurosci 8:194-201. CrossRef Medline

Mortin LI, Stein PS (1989) Spinal cord segments containing key elements of the central pattern generators for three forms of scratch reflex in the turtle. J Neurosci 9:2285-2296. Medline

Mortin LI, Keifer J, Stein PS (1985) Three forms of the scratch reflex in the spinal turtle: movement analyses. J Neurophysiol 53:1501-1516. Medline

Moult PR, Cottrell GA, Li WC (2013) Fast silencing reveals a lost role for reciprocal inhibition in locomotion. Neuron 77:129-140. CrossRef Medline

Parkis MA, Dong X, Feldman JL, Funk GD (1999) Concurrent inhibition and excitation of phrenic motoneurons during inspiration: phase-specific control of excitability. J Neurosci 19:2368-2380. Medline

Populin LC (2005) Anesthetics change the excitation/inhibition balance that governs sensory processing in the cat superior colliculus. J Neurosci 25:5903-5914. CrossRef Medline

Pratt CA, Jordan LM (1987) Ia inhibitory interneurons and Renshaw cells as contributors to the spinal mechanisms of fictive locomotion. J Neurophysiol 57:56-71. Medline

Robertson GA, Stein PS (1988) Synaptic control of hindlimb motoneurones during three forms of the fictive scratch reflex in the turtle. J Physiol 404:101-128. Medline

Ruigrok TJ, Crowe A, ten Donkelaar HJ (1984) Morphology of lumbar motoneurons innervating hindlimb muscles in the turtle pseudemys scrìpta elegans: an intracellular horseradish peroxidase study operation procedure. J Comp Neurol 230:413-425. CrossRef Medline

Sasaki K, Brezina V, Weiss KR, Jing J (2009) Distinct inhibitory neurons exert temporally specific control over activity of a motoneuron receiving concurrent excitation and inhibition. J Neurosci 29:11732-11744. CrossRef Medline

Shefchyk SJ, Jordan LM (1985) Excitatory and inhibitory postsynaptic potentials in alpha-motoneurons produced during fictive locomotion by stimulation of the mesencephalic locomotor region. J Neurophysiol 53: 1345-1355. Medline

Shu Y, Hasenstaub A, McCormick DA (2003) Turning on and off recurrent balanced cortical activity. Nature 423:288-293. CrossRef Medline

Silver RA (2010) Neuronal arithmetic. Nat Rev Neurosci 11:474-489. CrossRef Medline

Stein PS (2010) Alternation of agonists and antagonists during turtle hindlimb motor rhythms. Ann N Y Acad Sci 1198:105-118. CrossRef Medline

Stein PS, Robertson GA, Keifer J, Grossman ML, Berenbeim JA, Lennard PR (1982) Motor neuron synaptic potentials during fictive scratch reflex in turtle. J Comp Physiol 146:401-409. CrossRef

Stepien AE, Tripodi M, Arber S (2010) Monosynaptic rabies virus reveals premotor network organization and synaptic specificity of cholinergic partition cells. Neuron 68:456-472. CrossRef Medline

Takei T, Seki K (2013) Spinal premotor interneurons mediate dynamic and static motor commands for precision grip in monkeys. J Neurosci 33: 8850-8860. CrossRef Medline

Talpalar AE, Endo T, Löw P, Borgius L, Hägglund M, Dougherty KJ, Ryge J, Hnasko TS, Kiehn O (2011) Identification of minimal neuronal 
networks involved in flexor-extensor alternation in the mammalian spinal cord. Neuron 71:1071-1084. CrossRef Medline

Tresch MC, Kiehn O (2000) Motor coordination without action potentials in the mammalian spinal cord. Nat Neurosci 3:593-599. CrossRef Medline

Ulfhake B, Cullheim S (1988) Postnatal development of cat hind limb motoneurons. III: changes in size of motoneurons supplying the triceps surae muscle. J Comp Neurol 278:103-120. CrossRef Medline

van Vreeswijk C, Sompolinsky H (1996) Chaos in neuronal networks with balanced excitatory and inhibitory activity. Science 274:1724-1726. CrossRef Medline

Vogels TP, Rajan K, Abbott LF (2005) Neural network dynamics. Ann Rev Neurosci 28:357-376. CrossRef Medline
Wallén P, Shupliakov O, Hill RH (1993) Origin of phasic synaptic inhibition in myotomal motoneurons during fictive locomotion in the lamprey. Exp Brain Res 96:194-202. Medline

Walløe S, Nissen UV, Berg RW, Hounsgaard J, Pakkenberg B (2011) Stereological estimate of the total number of neurons in spinal segment D9 of the red-eared turtle. J Neurosci 31:2431-2435. CrossRef Medline

Wehr M, Zador AM (2003) Balanced inhibition underlies tuning and sharpens spike timing in auditory cortex. Nature 426:442-446. CrossRef Medline

Wu G, Perlmutter SI (2013) Sensitivity of spinal neurons to GABA and glycine during voluntary movement in behaving monkeys. J Neurophysiol 109:193-201. CrossRef Medline 